\title{
La salud periodontal como estrategia para el desarrollo social
}

\author{
Ana Laura Mendoza López*
}

Hoy en día, nos encontramos ante cifras alarmantes en materia de salud que obligan a reflexionar y a tomar acción urgente por parte de nosotros como profesionales para contrarrestar y generar en la sociedad un espacio que se traduzca en acciones preventivas. En México, la enfermedad periodontal es una de las principales causas de pérdida temprana de dientes en adultos jóvenes y, como bien muestra la literatura, la prevalencia aumenta por el incremento en la edad de la población. Si bien la enfermedad periodontal tiene un gran potencial preventivo, la epidemiología nos muestra un escenario que exige la creación de campañas o programas enfocados a la difusión de información en materia de salud periodontal y su relación con la salud en general.

Por otra parte, se entiende como desarrollo social a la evolución y el mejoramiento en las condiciones de vida de los individuos de una sociedad, lo cual tiene impacto en el desarrollo del capital humano de todo un país.

En la actualidad, contamos con una odontología con gran potencial de desarrollo; no obstante, se muestra ante una crisis al ser ajena en el enfoque de la salud pública, es aquí donde cabe la pregunta: ¿de qué sirve contar con adelantos científicos y

\footnotetext{
* Cirujano Dentista Especialista en Periodoncia. Periodoncista Civil en turno de la Secretaría de la Defensa Nacional en la Ciudad de Veracruz, Veracruz.
}

Este artículo puede ser consultado en versión completa en www.medigraphic.com/periodontologia tecnológicos en la odontología si no se tiene un impacto directo en la comunidad? En este sentido, podemos observar cómo las redes sociales están llenas de promoción de estética dental, y que en gran parte de los casos (quienes sabemos del tema) podemos apreciar el descuido en la salud periodontal; sin embargo, en ocasiones la población no logra detectarlo al no tener el conocimiento ni el acceso a la información de nuestra área, y como consecuencia se dejan llevar sólo por los resultados de una sonrisa blanca que tarde o temprano fracasará por no tener las consideraciones periodontales adecuadas.

Si bien todos los odontólogos generales y especialistas que año con año nos mantenemos actualizados al acudir a distintos foros de discusión, congresos nacionales e internacionales, y que inclusive contamos con este excelente espacio como es la Revista Mexicana de Periodontología, tenemos el acceso a todo este mundo que abarca la periodoncia, por lo que estamos preparados para recibir y dar solución a los problemas con los que acuden nuestros pacientes al consultorio. Sin embargo, considero que el problema está un paso antes: en la falta de coordinación con todo el sector salud en la difusión oportuna de toda la información acerca de la prevención en la salud periodontal; incluso podemos darnos cuenta de esta deficiencia al platicar con médicos generales y médicos especialistas, quienes reciben escasa información en su formación profesional acerca de la relación de la salud bucal y la salud en general. Por lo tanto, es de suma importancia comenzar a trabajar en equipo. De esta manera, no sólo se reduce la prevalencia de enfermedades bucodentales sino 
que se engloba como parte de un sistema general que incluyen enfermedades sistémicas.

Es tiempo de descentralizar la información, que salga de las aulas y de los espacios dirigidos únicamente a odontólogos y comenzar una nueva era de consciencia periodontal. Tenemos una oportunidad como profesionistas de trabajar por la salud de las personas, de integrarnos a los equipos de salud, de adquirir nuevos roles como ciudadanos y, por ende, de causar un impacto social de manera positiva.

Correspondencia:

C.D.E.P. Ana Laura Mendoza López

E-mail: analaura.perio@gmail.com 